\title{
Detection of autoantibodies against islet amyloid polypeptide in human serum. Lack of association with Type 1 (insulin-dependent) diabetes mellitus, or with conditions favouring amyloid deposition in islets
}

\author{
F.K.Gorus ${ }^{1}$, J.-C.Sodoyez ${ }^{2}$, D. G.Pipeleers ${ }^{1}$, B.Keymeulen ${ }^{1}$, A.Foriers ${ }^{1}$, C.F.H. Van Schravendijk ${ }^{1}$ and the Belgian \\ Diabetes Registry ${ }^{3}$ \\ ${ }^{1}$ Department of Metabolism and Endocrinology, Vrije Universiteit Brussel, Brussels; \\ ${ }^{2}$ Department of Endocrinology, CHU Sart-Tilman, Université de Liège, Liège; \\ ${ }^{3}$ BDR, Brussels, Belgium
}

\begin{abstract}
Summary. A radiobinding assay for the detection of autoantibodies against islet amyloid polypeptide was developed, analytically validated, and -in parallel with a similar assay for the detection of autoantibodies against insulin - applied to sera from recent-onset Type 1 (insulin-dependent) diabetic patients and from age- and sex-matched control subjects. There was no difference in islet amyloid polypeptide autoantibody titres between patient groups and matched control subjects, nor within subject groups according to age. At onset of Type 1 diabetes, elevated islet amyloid polypeptide-autoantibody levels ( $>97$ th percentile of control subjects) were only detected in 1 of 30 patients aged $0-19$ years and in 2 of 35 patients aged $20-39$ years. By contrast, insulin autoantibodies were frequently demonstrated, in particular at onset of diabetes under age 20 (0-19 years: 18 of 30 patients; 20 39 years: 10 of 35 patients; $p<0.01$ vs matched control sub-
\end{abstract}

jects). Islet amyloid polypeptide autoantibodies were not detectable in 3 insulinoma patients nor in 37 patients (aged 3370 years) with Type 2 diabetes (vs 1 of 40 in matched control subjects). In positive serum, adsorption onto protein A-Sepharose removed islet amyloid polypeptide binding activity, hereby confirming its antibody nature. In conclusion, Type 1 diabetes is associated with an age-dependent autoantibody reaction against insulin but not against islet amyloid polypeptide. Conditions associated with amyloid deposition in islets (Type 2 diabetes, insulinoma and ageing) do not favour the formation of autoantibodies against islet amyloid polypeptide.

Key words: Islet amyloid polypeptide, autoantibodies, Type 1 (insulin-dependent) diabetes mellitus, Type 2 (noninsulin-dependent) diabetes mellitus, amyloid, ageing.
Clinical onset of Type 1 (insulin-dependent) diabetes mellitus is often accompanied by the presence of circulating $\operatorname{IgG}$ which bind to islet cell antigens $[1,2]$. The diabetesspecificity of these autoantibodies and their appearance before clinically overt disease fuelled the concept of a relatively long pre-clinical stage, during which detection of autoimmune markers would allow prediction of the disease [3-6]. So far, islet cell cytoplasmic antibodies (ICA) have been most commonly used in long-term follow-up studies of groups at risk for Type 1 diabetes [4-6]. They are consequently best characterized in terms of positive predictive value depending upon age of disease onset, antibody titre and persistence.

With the characterization of Beta-cell specific targets for circulating immunoglobulins [7-10], more quantitative immunoassays can be designed for large-scale evaluation. Antibodies against glutamate decarboxylase, insulin and proinsulin have been identified and their presence can complement information gained from ICA testing. For example, simultaneous positivity for ICA and insulin autoantibodies (IAA) has been claimed to confer greater risk for subsequent development of Type 1 diabetes than positivity for either test alone [1-3,11-14]. No pathogenic role has so far been ascribed to these autoantibodies. Rather it is conceivable that they arise as a consequence of inappropriate Beta-cell specific antigen expression or presentation during autoimmune insulitis and cellular destruction. Various Beta-cell specific (secretory) peptides can thus be considered as candidate targets for diabetes-associated autoantibodies. In the search for new, perhaps complementary, immune markers of Type 1 diabetes, the present study was designed to investigate whether the autoantibody response mounted against Beta cells might also involve islet amyloid polypeptide (IAPP) and if so, whether the occurrence of autoantibodies against this Beta-cell secretory peptide [15-17] parallels or complements that directed against the other secretion product, insulin. To this effect we have developed a radiobinding assay (RBA) for detection of IAPP autoantibodies (IAPP-AA) in human serum. In the specific case of IAA, RBA assays have been shown to surpass ELISA-technology in recognizing diabetes-associated autoantibodies [18-22]. Like other islet-cell specific auto- 


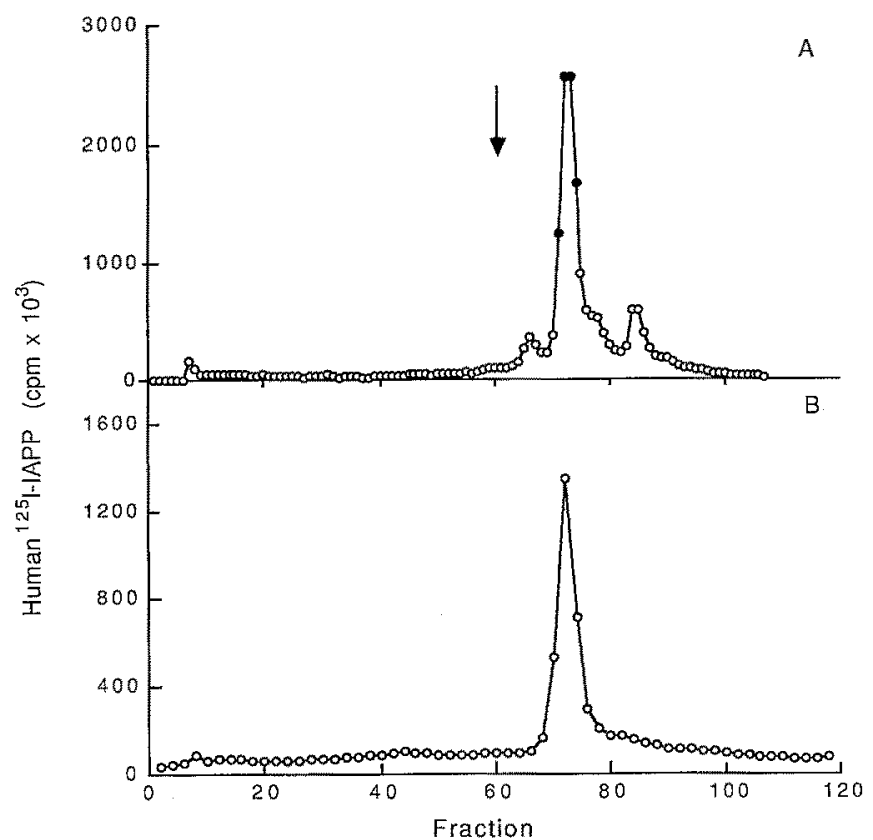

Fig. 1A,B. HPLC-profile of radioactivity after iodination of human islet amyloid polypeptide (IAPP)-amide with $\mathrm{Na}^{125} \mathrm{I}$. A, profile obtained immediately after iodination by determining the amount of radioactivity per $10 \mu \mathrm{l}$ of each fraction in a gamma-counter; fractions 71 to $74(-)$ were pooled and used as tracer. The arrow indicates the position of unlabelled IAPP. B, profile of tracer sample from pooled fractions (A) after 34 days of storage at $4^{\circ} \mathrm{Cin} 2 \mathrm{~mol} / /$ acetic acid with $2.5 \mathrm{~g} / 1$ bovine serum albumin ( $\mathrm{vol} / \mathrm{vol})$, in this case the entire fractions were counted

antibodies that precede or accompany clinical onset of Type 1 diabetes, IAA belong to the IgG-class. Diabetesassociated IAA display high affinity [22]. Clinical manifestations of autoimmune diseases are believed to be accompanied or preceded by transition from early IgM autoantibodies to IgG-autoantibodies and by affinity maturation [23]. Because high affinity autoantibodies are likely to be clinically more relevant and are most reliably detected by RBA, after validation of the latter methodology we selected it for IAPP-AA determination. In parallel with a similar RBA for IAA, the IAPP-AA assay was applied to sera from 65 patients at onset of Type 1 diabetes and from an equal number of age-and sex-matched control subjects. An additional goal of the study was to look for the possible occurrence of IAPP-AA in association with Type 2 diabetes or with other conditions such as insulinoma and ageing that are, albeit to variable degrees, characterized by a propensity to form amyloid deposits. This abnormal material, mainly composed of IAPP [15-17], could become antigenic in an older population with an overall increased tendency towards autoantibody formation $[24,25]$.

\section{Subjects and methods}

\section{Subjects}

Sixty-six Type 1 diabetic patients (aged 0-39 years at clinical onset) were recruited through the Belgian Diabetes Registry, a data and sample bank for Type 1 diabetic patients and their first degree rela- tives [26]. Only patients from whom blood was sampled before or within 7 days after initial insulin treatment were enrolled. The group consisted of 30 patients ( 15 male and 15 female) aged $0-19$ years at onset (median age 9 years) and 35 patients ( 24 male and 11 female) aged 20-39 years (median age 34 years). Venous blood was collected in dry plastic tubes (Sarstedt, Essen, Belgium), allowed to clot at room temperature, centrifuged within $2 \mathrm{~h}$ at $1000 \mathrm{~g}$ for $15 \mathrm{~min}$, divided in $200 \mu \mathrm{l}$ aliquots and stored at $-80^{\circ} \mathrm{C}$ until assayed. We also sampled blood from 37 patients with Type 2 (non-insulin-dependent) diabetes (aged 33-70 years; median age 62 years; 20 male and 17 female) and three patients with insulinoma (aged 34, 61 and 69 years; two male and one female). The diagnosis of Type 1 and Type 2 diabetes was made according to the criteria of the National Diabetes Data Group [27]. In Type 2 diabetic patients, disease duration ranged from 1 month up to 23 years (median duration 8 years). One patient was treated with diet alone, while 10 patients were on oral hypoglycaemic drugs, nine on insulin therapy and the remainder on combination therapy. For each patient group an equal number of age- and sex-matched healthy control subjects was selected. This group included blood donors and healthy laboratory workers ( $>18$ years old), as well as children $(0-18$ years) attending the participating clinical centres for minor surgery $[25,26]$. Before the start of the study, it was agreed that the control subjects would not be informed of assay results and would not be submitted to any form of questioning or additional testing.

\section{Assay of autoantibodies}

Insulin autoantibodies (IAA) were determined by a radiobinding assay (RBA), according to a modification [28] of the method of Palmer [7,29]. Briefly, human mono ${ }^{125} \mathrm{I}$-tyrosine-A14 insulin (theoretical specific activity: $360 \mu \mathrm{Ci} / \mu \mathrm{g}$ ) was prepared by chloramine Tiodination and HPLC-purification of recombinant insulin (crystalline human insulin, Humulin; kindly donated by E. Lilly Corp., Indianapolis, Ind., USA) [30]. After removal of free and antibody-bound endogenous insulin by acid-charcoal extraction, supernatants were incubated with human ${ }^{125} \mathrm{I}$-insulin for $18 \mathrm{~h}$ at $4^{\circ} \mathrm{C}(10-20000 \mathrm{cpm} / \mathrm{tube})$, and the amount of antibody-bound tracer was measured in the pellets formed by polyethylene glycol precipitation of immunoglobulins. For each sample, total tracer binding was corrected for non-specific binding (NSB) by subtracting the counts obtained under identical conditions except for the presence of an excess of unlabelled insulin $\left(10^{-6} \mathrm{~mol} / \mathrm{l}\right)$. Serum samples were run in duplicate. IAA-activity was expressed as ${ }^{125} \mathrm{I}$-insulin-binding capacity according to the formula:

$\%$ tracer bound $=$

mean cpm samples - mean cpm samples with excess unlabelled insulin mean cpm total counts $(n=5)$

NSB generally amounted to $1 \%$ of total counts. Results were rejected and samples re-tested when duplicates differed by more than $10 \%$. The sensitivity of the assay was optimized by doubling the final concentration of bovine scrum albumin (BSA, RIA grade; Sigma Chemical Co, St.Louis, Mo., USA; $10 \mathrm{~g} / \mathrm{l}$ ) and of bovine gamma globulin (BGG, 99\% purity; Sigma, $5 \mathrm{~g} / \mathrm{l}$ ) in the assay mixture as compared to the original protocol of Palmer [7, 28, 29]. Over a 6month period, between-assay coefficient of variation (CV) equalled $10.2 \%, 10.8 \%$ and $30.0 \%$, respectively for internal quality control sera with IAA amounting to $12.7 \%, 6.5 \%$ (both IAA-positive) and $0.3 \%$ (IAA-negative serum) of tracer bound. The assay was validated in the 1990 - Immunology of Diabetes Workshop (IDW) for IAA where it detected IAA in 12 of $30(40 \%)$ patients with Type 1 diabetes, in 7 of $22(32 \%)$ first degree relatives of patients, in 5 of 8 $(63 \%)$ pre-diabetic subjects and 0 of $61(0 \%)$ healthy control subjects.

The IAPP-AA-assay was also based on a radiobinding procedure. Mono human ${ }^{125}$ I-IAPP (theoretical specific activity: 


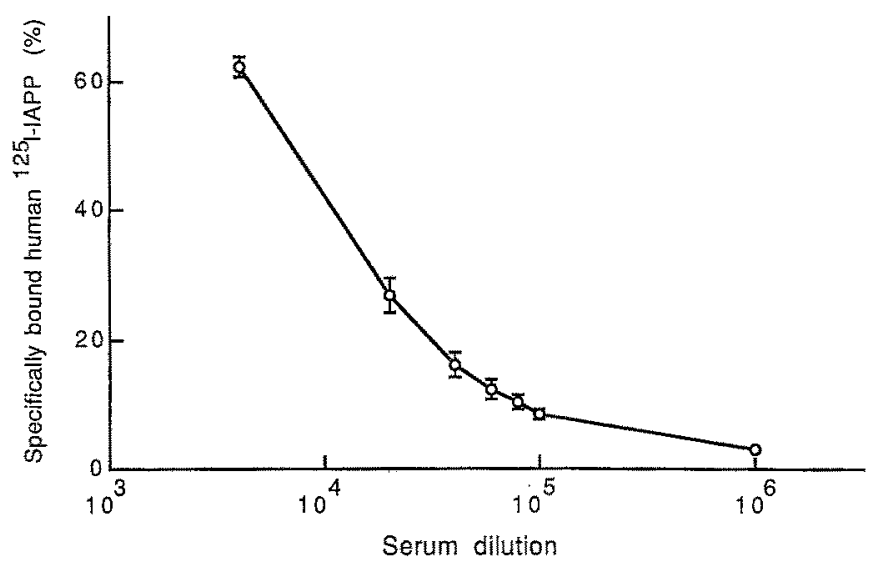

Fig.2. Reactivity of human ${ }^{125}$-islet amyloid polypeptide (IAPP) tracer with increasing dilutions of rabbit anti-rat IAPP-amide serum. Experimental results represent mean values $\pm S E M$ of five independent experiments. All individual points were corrected for non-specific binding obtained in similar conditions except for the presence of an excess unlabelled IAPP

$550 \mu \mathrm{Ci} / \mu \mathrm{g})$ was prepared by iodination of human IAPP amide (Peninsula Laboratory, Inc., Belmont, Calif., USA) according to a modification of the chloramine $T$ method [30]. Briefly, human IAPPamide $\left(10 \mu \mathrm{g}\right.$ freshly dissolved in $10 \mu 10.1 \mathrm{~mol} / 1 \mathrm{NaH}_{2} \mathrm{PO}_{4}, 0.1 \%$ Triton X-100, pH 3.2) was first mixed with $25 \mu \mathrm{l} 0.1 \mathrm{~mol} / \mathrm{l}$ phosphate buffer, $0.1 \%$ Triton X-100, $\mathrm{pH} 7.6$, and $10 \mu \mathrm{Na}{ }^{125} \mathrm{I}(100 \mathrm{mCi} / \mathrm{ml}$, IMS-30; Amersham International, Amersham, Bucks, UK). The reaction was initiated by pipetting $25 \mu \mathrm{l}$ chloramine $\mathrm{T}$ ( $4.2 \mu \mathrm{g}$ added in $25 \mu$ phosphate buffer, $0.1 \%$ Triton $\mathrm{X}-100, \mathrm{pH} 7.6)$ and stopped $90 \mathrm{~s}$ later by addition of $25 \mu \mathrm{INa} \mathrm{S}_{2} \mathrm{O}_{5}(0.4 \mathrm{mg} / \mathrm{ml}$ in $0.02 \mathrm{~mol} / \mathrm{l}$ phosphate buffer, $0.1 \%$ Triton $\mathrm{X}-100, \mathrm{pH} 7.6)$. The oxidation reaction proceeded at $4^{\circ} \mathrm{C}$ under gentle stirring. ${ }^{125}$ I-IAPP was then purified by HPLC using a $\mu$ Bondapack $\mathrm{C} 18$ column and an acetonitrile gradient in ethanolamine buffer ( $\mathrm{pH}$ 2.5). One single major peak eluted at $35 \mathrm{ml}$. Fractions of interest were pooled and mixed with an equal volume of $2 \mathrm{~mol} / 1$ acetic acid containing $2.5 \mathrm{~g} / 1 \mathrm{BSA}$ and stored at $4^{\circ} \mathrm{C}$ until use (Fig. $1 \mathrm{~A}$ ). In order to avoid polymerization, the tracer was never dried out and all assay solutions were supplemented with $0.1 \%$ Triton X-100. Serum samples to be assayed for IAPP-AA were not first treated by acid-charcoal because their IAPP concentration $(2-6 \mathrm{pmol} / \mathrm{l})$ [31] is so low that, according to the law of mass action, formation of IAPP-anti-IAPP immune complexes becomes negligible, even in the presence of very high affinity antibodies $\left(\mathrm{K}=10^{10} \mathrm{1} / \mathrm{mol}\right)$ [32]. Furthermore, omission of the acid charcoal step avoids a four-fold dilution, thereby increasing assay sensitivity. Like for IAA, all samples were run in duplicate and data corrected for NSB, by a parallel assay of binding in the presence of an excess of unlabelled IAPP $\left(5.10^{-7} \mathrm{~mol} / /\right.$ final $)$. Typically, NSB averaged $1-2 \%$ of total counts. Less than $10 \%$ difference between duplicates was tolerated.

Islet cell cytoplasmic antibodies (ICA) were measured by means of an indirect immunofluorescence technique using cryosections of fresh-frozen human pancreas (blood group O) for substrate [33]. Results were expressed as Juvenile Diabetes Foundation (JDF) units. Sera with less than 6 JDF units were considered to be negative. The test was clinically validated through repeated participation in external quality control programmes [34].

Serum $\mathrm{IgG}$ were removed by applying $400 \mu \mathrm{l}$ of serum diluted volume/volume in phosphate buffered saline, $\mathrm{pH} 8.0$, onto a protein A-Sepharose mini-column (Pharmacia, LKB, Brussels, Belgium; $1.5 \mathrm{mg}$ of powder swollen to $5 \mathrm{ml}$ in phosphate buffered saline, $\mathrm{pH}$ 8.0) and eluting with phosphate buffered saline, $\mathrm{pH}$ 8.0. The absorbance of the eluate was monitored at $277 \mathrm{~nm}$ wavelength. The flowthrough fractions were collected and concentrated to the original volume in Centricon 30 filters (Amicon, Brussels, Belgium).

\section{Statistical analysis}

For IAPP-AA-titres the statistical significance of differences between experimental groups was assessed by a two-tailed MannWhitney U test. In case of multiple comparisons $p$-values were corrected $\left(p_{c}\right)$ by means of Bonferroni-adjustments and statistical significance was defined as $p$ or $p_{\varepsilon}<0.05$. For comparison of prevalences, the chi-square test was used.

\section{Results}

Analytical validation of a radiobinding $(R B A)$-assay for $I A P P$-autoantibody determination (IAPP-AA)

Figure 1 A shows the HPLC elution profile of radioactiv ity following iodination of human IAPP. Fractions 71 to 74 were pooled and stored as described under methods until use in the RBA. After 5 weeks of storage, the tracer eluted at the same position in HPLC (Fig. 1B); its elution on Sephadex G50 columns also remained identical to that of freshly labelled rat IAPP, which is known not to polymerize [15-17] (data not shown).

As illustrated in Figure 2, the elaborated RBA was able to consistently detect IAPP-antibodies (expressed as $\%$ human mono ${ }^{125}$ I-IAPP specifically bound) in a hyperimmune rabbit anti-rat IAPP-amide serum. The magnitude of the IAPP-binding activity varied conversely to serum dilution (Fig.2), dropping from $62 \%$ at 1:4000 to $3 \%$ at $1: 10^{6}$. Over a 3 -month period, between-run imprecision of the assay was evaluated by cumulating results obtained in 15 different experiments for a normal control serum as well as for two different dilutions of hyperimmune rabbit anti-rat IAPP-amide serum in IAPP-AA-negative serum. Interassay CV $(n=15)$ amounted to $25.7 \%$, $12.6 \%$ and $11.7 \%$, respectively for a level of specific tracer binding corresponding to $1.5 \%(\mathrm{SD}=0.4 \%), 6.7 \%$ $(\mathrm{SD}=0.8 \%)$ and $13.8 \%(\mathrm{SD}=1.6 \%)$.

\section{Determination of IAPP-AA in patient sera: lack of association with disease and established markers}

Figure 3 represents the distribution of IAPP-AA-titres obtained in the various populations studied. IAPP-binding activity was not significantly different between patients suffering from Type 1 or Type 2 diabetes and their age- and sex-matched control subjects, nor between different age groups of healthy control subjects $\left(p_{c}>0.05\right)$. A small number of patients ( 5 of 102), but also of control subjects ( 4 of 102), displayed more than $2 \%$ tracer binding. In two patients and one control subject, tracer binding was higher than $15 \%$. Varying the cutoff level for IAPPAA-positivity between the 90th and 99th percentiles of matched control subjects did not lead to significant differences in IAPP-AA-prevalence in any of the patient groups studied ( $p_{\mathrm{c}}>0.05$ with chi-square test). There was no association between IAPP-AA-positivity and presence of ICA or IAA in patients with Type 1 diabetes nor in control subjects. IAPP-AA were not detectable in three patients with insulinoma. Absorption of $\sim 90 \%$ of serum IgG by protein A-Sepharose decreased the IAPP- 

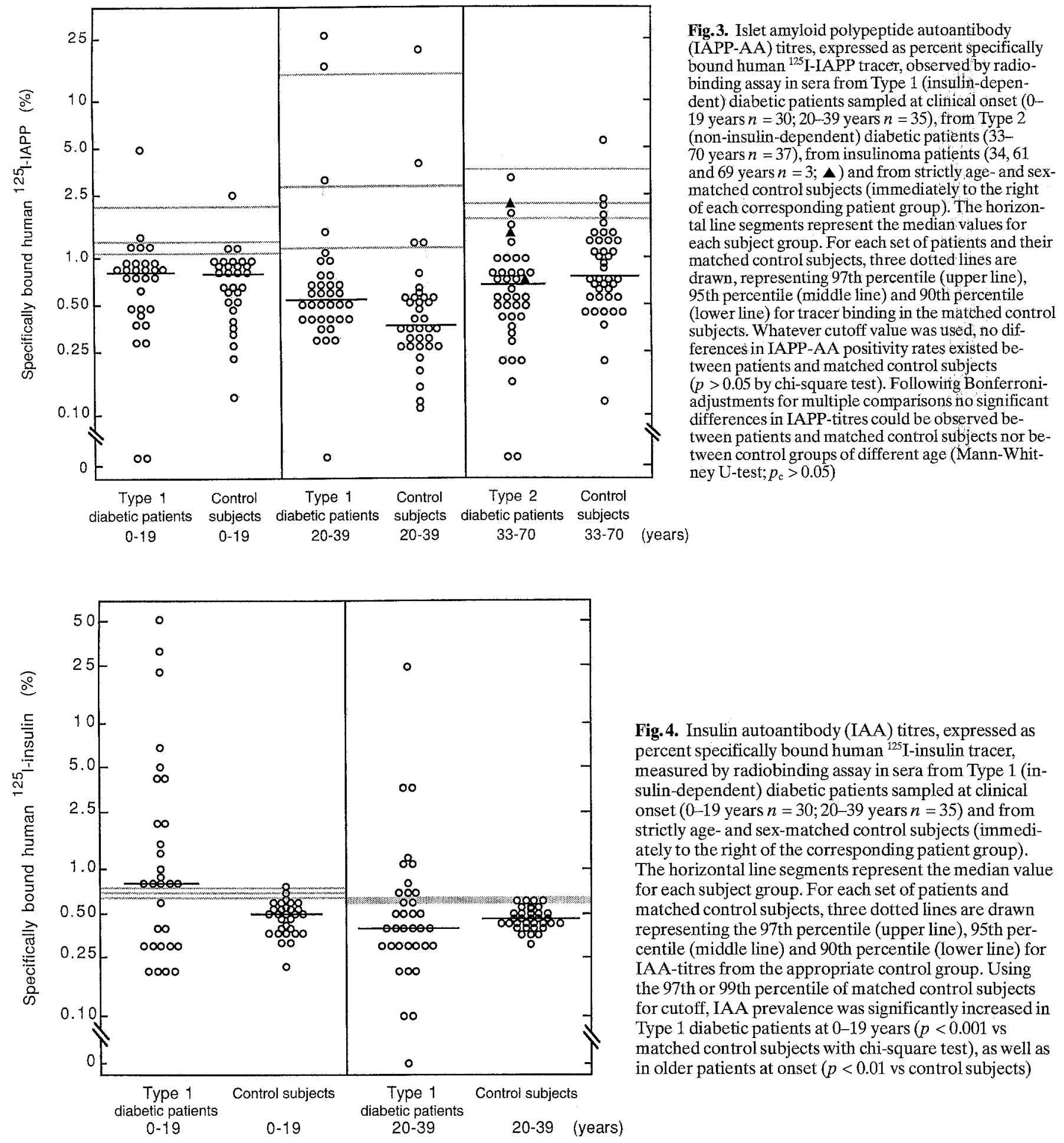

Fig. 4. Insulin autoantibody (IAA) titres, expressed as percent specifically bound human ${ }^{125}$ I-insulin tracer, measured by radiobinding assay in sera from Type 1 (insulin-dependent) diabetic patients sampled at clinical onset $(0-19$ years $n=30 ; 20-39$ years $n=35)$ and from strictly age- and sex-matched control subjects (immediately to the right of the corresponding patient group). The horizontal line segments represent the median value for each subject group. For each set of patients and matched control subjects, three dotted lines are drawn representing the 97 th percentile (upper line), 95th percentile (middle line) and 90 th percentile (lower line) for IAA-titres from the appropriate control group. Using the 97 th or 99 th percentile of matched control subjects for cutoff, IAA prevalence was significantly increased in Type 1 diabetic patients at $0-19$ years $(p<0.001$ vs matched control subjects with chi-square test), as well as in older patients at onset ( $p<0.01$ vs control subjects)

AA or IAA titres by more than $70 \%$ in strongly IAPPAA- or IAA-positive human sera. This observation is taken as evidence that in both instances the high affinity peptide-binding activity measured by RBA is due to the presence of specific IgG.

In marked contrast to the lack of association of IAPPAA with clinical onset of Type 1 diabetes, ICA and IAA were frequently present in this patient group (Fig.4). As expected, ICA-positivity ( $\geq 6 \mathrm{JDF}$ units) was frequently noted in Type 1 diabetic patients ( 27 of 30 or $90 \%$ in the group aged $0-19$ years at onset vs 25 of 35 or $71 \%$ in the group aged 20-39 years at onset; $p>0.05$ ). Regarding IAA, the \% specifically bound insulin tracer exceeded the 97 th (as well as the 99 th) percentile of matched control subjects in 18 of $30(60 \%)$ patients with onset of Type 1 diabetes before 20 years, with values ranging between 0.2 and $50.8 \%$ binding vs 0.2 to $0.8 \%$ in matched control subjects ( 1 of 30 , i.e. $3 \%$, above the 97 th percentile corresponding to $0.7 \%$ binding; $p<0.001$ by chisquare test). In agreement with previous reports [35, 36], 
patients with Type 1 diabetes aged $20-39$ years at onset displayed lower IAA-prevalence (10 of 35 , i.e. $29 \%$, above the 97 th percentile corresponding to $0.6 \%$ binding vs 1 of 35 , i.e. $3 \%$, in matched control subjects; $p<0.01$ by chi-square test) and lower IAA-titres ( $p<0.05$ by Mann-Whitney U test) as compared to patients aged 0-19 years at onset of Type 1 diabetes. For comparison, IAPP-AA titres exceeded 97 th percentile only in 1 of 30 (3\%) patients with Type 1 diabetes with onset before 20 years vs 1 of $30(3 \%)$ in matched control subjects and in 2 of $35(6 \%)$ patients with onset of Type 1 diabetes between $20-39$ years vs 1 of $35(3 \%)$ in matched control subjects (Fig.3).

\section{Discussion}

A search for IAPP-AA in Type 1 diabetic patients can provide information complementary to that derived from currently assayed antibodies. Disease-specific occurrence of immunoglobulin binding to IAPP would indicate that autoantibody formation in Type 1 diabetes is not restricted to one secretory product of the pancreaticBetacell, namely insulin, but includes a reactivity against other constituents of the Beta-cell secretory vesicle as already shown for carboxypeptidase $\mathrm{H}$ [37]. In view of the Beta-cell specificity of IAPP, IAPP-binding immunoglobulin could serve as a simple and quantitative marker for detection of Beta cell selective autoimmune reaction. In the present study, however, increased prevalence or titres of IAPP-AA were not detected at clinical onset of Type 1 diabetes. Although a transient presence of IAPP-AA during a preclinical phase of the disease may not be excluded, our negative finding raises the intriguing possibility of selectivity in antibody formation against certain Beta-cell specific peptides.

Although it is capable of measuring IAPP-binding immunoglobulin, our RBA detected only few patients with circulating IAPP-AA. No difference in IAPP-AA-prevalence was found between Type 1 diabetic patients $(5 \%)$ and age-matched control subjects $(3 \%)$ whereas IAA occurred in $43 \%$ of the Type 1 patients vs $3 \%$ in control subjects. Using an ELISA-technique, Clark et al. [38] noticed a higher prevalence of IAPP-AA in Type 1 and Type 2 diabetic patients than in normal control subjects. These discrepant observations may have originated from the use of different assay systems $[20,32,39]$. Whereas ELISA is to be considered as a capacity assay, the RBA-signal depends on both antibody concentration and affinity. When both techniques were applied to a series of insulin (auto)antibodies, no correlation between ELISA- and RBA-titres was found [18]. Moreover, the two techniques are not always concordant in classifying samples as antibody-positive or negative. Positivity in ELISA only suggests the presence of high capacity low-affinity antibodies, whereas positivity in RBA merely indicates the occurrence of low-capacity high-affinity antibodies $[32,39]$. Association of IAA with Type 1 diabetes has been demonstrated by RBA but not by ELISA [21] leading to the conclusion that RBA is superior to ELISA in detecting IAA in Type 1 diabetes at onset and in relatives at high risk for the disease [21,22].
Our negative findings cannot be attributed to inadequacy of the tracer. The prepared mono- ${ }^{125}$ I-IAPP did not exhibit altered charge or hydrophobicity as judged by repeated HPLC chromatography over a 5-week period. It did not undergo polymerization during storage as indicated by gel filtration. Successive testing over a 3-month period illustrated its specific binding to a hyperimmune serum in a reproducible and dose-dependent manner. We consider it unlikely that IAPP-AA were technically undetectable as a result of complex formation with the circulating peptide, since plasma IAPP levels are extremely low. Of course it cannot be excluded that circulating IAPP-AA are directed towards an epitope containing the C-terminal tyrosine-amide making them unreactive with iodinated IAPP.

The significance of IAPP-AA of the IgG class in sera of a minority of patients and control subjects is unknown. Their lack of relationship with age, sex and disease would suggest that they are "natural" antibodies [40] rather than the consequence of an imbalance within the immune system resulting in a disruption of tolerance [41].

It is at present not known why Type 1 diabetes would be associated with autoantibodies against one (insulin) and not another (IAPP) of the Beta-cell specific secretory products. Antigenicity of peptides is a complex matter depending upon parameters such as molecular weight, prevailing concentration and molecular mobility [42-44]. In this respect, it is interesting to note that proinsulin is reputed to be more immunogenic than insulin although the naturally formed antibodies are usually directed towards the insulin moiety or either one of the C-peptide-insulin junctions $[39,45]$. The smaller size of IAPP, its lower concentration in the Beta cell and in the systemic circulation, as well as its propensity to adopt the less mobile Betapleated sheet configuration [15-17] might all contribute to reducing the immunogenicity of IAPP relative to (pro)insulin.

IAPP-antibodies were not detected in conditions with extracellular accummulations of IAPP-polymers, such as in ageing, Type 2 diabetes and insulinoma. In these deposits, IAPP is no longer monomeric but polymerized so that antibodies, directed against a conformational epitope that is exclusively present in the polymer, will escape detection using a radiolabelled monomer of IAPP.

In conclusion, an RBA for IAPP-AA was developed and validated. It detected high affinity IgG-IAPP-AA in a few patients with Type 1 and Type 2 diabetes, as well as in control subjects of various age groups. No preferential association of IAPP-AA with either type of diabetes or progressing age could be demonstrated. On the other hand, Type 1 diabetic patients presented a higher prevalence of insulin antibodies. Thus, in this disease, for reasons unknown, certain Beta-cell specific peptides appear not to trigger autoantibody production.

Acknowledgements. We would like to thank the following members of the Belgian Diabetes Registry for recruiting patients and control subjects for this study and assisting in the handling of samples: Drs. A. Bodson (Jumet), J.L. Coolens (Hasselt), W. Coucke (Roeselare), R. Craen (Gent), J.C.Daubresse (Charleroi), T.Decraene (Brussels), I. De Leeuw (Antwerp), C.Delvigne (Antwerp), H. Dorchy (Brussels), F. Féry (Brussels), C. Gillet (Brussels), G. Krzentowski 
(Jumet), G. Lamberigts (Brugge), D. Nicolaji (Kortrijk), R. Rottiers (Gent), A. Scheen (Liège), O. Segers (Brussels), G. Somers (Brussels), K. Van Acker (Antwerp), P. Van Crombrugge (Aalst), C. Vandewalle (Brussels), L. Van Gaal (Antwerp), S. Van Imschoot (Brugge) and Mr. J. Vertommen (Antwerp). We are also endebted to Ms A.Demarré, Ms L. De Pree, Mr. P. Goubert, Ms A. Ivens, Ms F.Lebleu and Mr. G. Schoonjans for expert technical assistance, to Dr. C. Vandewalle (Belgian Diabetes Registry, Brussels) for continued logistic support, to Dr. G. Somers (Metabolic Unit, Academic Hospital VUB, Brussels) for sending blood samples from patients with Type 2 (non-insulin-dependent) diabetes mellitus and insulinoma, to Dr. M.Sangeleer (E. Lilly, Brussels, Belgium) for providing crystalline Humulin, and to Ms N. Van Slycke for excellent secretarial help. This work was supported by the Belgian Fonds voor Geneeskundig Wetenschappelijk Onderzoek (FGWO grant 3.9007. 91-94). Dr. F. Gorus is a recipient of a part-time FGWO scholarship for Fundamental Clinical Research.

\section{References}

1. Drell DW, Notkins AL (1987) Multiple immunological abnormalities in patients with type 1 (insulin-dependent) diabetes mellitus. Diabetologia 30: 132-143

2. Wilkin TJ (1991) Autoantibodies as mechanisms, markers, and mediators of B-cell disease. Diabetes Metab Rev 7: 105-120

3. Maclaren NK (1988) How, when and why to predict IDDM. Diabetes 37: 1591-1594

4. Tarn AC, Thomas JM, Dean BM et al. (1988) Predicting insulindependent diabetes. Lancet I: 845-850

5. Bruining GJ, Molenaar JL, Grobbe DE et al. (1989) Ten year follow-up study of islet cell antibodies and childhood diabetes mellitus. Lancet I: 1100-1103

6. Bonifacio E, Bingley PJ, Shattock M et al. (1990) Quantification of islet cell antibodies and prediction of insulin-dependent diabetes. Lancet 335: 147-149

7. Palmer JP, Asplin CM, Clemons P et al. (1983) Insulin antibodies in insulin-dependent diabetics before insulin treatment. Science 222: $1337-1339$

8. Baekkeskov S, Aanstoot H-J, Christgau S et al. (1990) Identification of the $64 \mathrm{~K}$ autoantigen in insulin-dependent diabetes as the GABA-synthesizing enzyme glutamic acid decarboxylase. Nature 347: 151-156

9. Christie MR, Brown TJ, Cassidy D (1992) Binding of antibodies in sera from type 1 (insulin-dependent) diabetic patients to glutamate decarboxylase from rat tissues. Evidence for antigenic and non-antigenic forms of the enzyme. Diabetologia 35: $380-$ 384

10. Kuglin B, Gries FR, Kolb H (1988) Evidence of IgG autoantibodies against human proinsulin in patients with IDDM before insulin treatment. Diabetes 37: 130-132

11. Karjalainen J, Knip M, Mutsonen A, Ilonen J, Åkerblom HK (1986) Relation between insulin antibody and complement-fixing islet cell antibody at clinical diagnosis of IDDM. Diabetes 35 : $620-622$

12. Ludvigsson J, Binder C, Mandrup-Poulsen T (1988) Insulin autoantibodies are associated with islet cell antibodies: their relation to insulin antibodies and B-cell function in diabetic children. Diabetologia 31: 647-651

13. Thivolet Ch, Beaufrère B, Bétuel H et al. (1988) Islet cell and insulin autoantibodies in subjects at high risk for development of type 1 (insulin-dependent) diabetes mellitus: the Lyon family study. Diabetologia 31: 741-746

14. Ziegler AG, Ziegler R, Vardi P et al. (1989) Life table analysis of progression to diabetes of anti-insulin autoantibody-positive relatives of individuals with type 1 diabetes. Diabetes 38: 13201325

15. Cooper GJS, Day AJ, Willis AC, Roberts AN, Raid KBM, Leighton B (1989) Amylin and the amylin genes: structure, function and relationship to islet amyloid and to diabetes mellitus. Biochim Biophys Acta 1014: 247-258
16. Nishi M, Sanke T, Nagamatsu S, Bell GI, Steiner DF (1990) Islet amyloid polypeptide. A new $\beta$-cell secretory product related to islet amyloid deposits. J Biol Chem 265: 4173-4176

17. Johnson KH, O'Brien TD, Westermark P (1991) Newly identified pancreatic protein islet amyloid polypeptide: what is its relationship to diabetes? Diabetes 40:310-314

18. Sodoyez-Goffaux F, Koch M, Dozio N, Brandenburg D, Sodoyez JC (1988) Advantages and pitfalls of radioimmune and enzyme linked immunosorbent assays of insulin antibodies. Diabetologia 31: 694-702

19. Palmer JP, Wilkin TJ, Kurtz AB, Bonifacio E (1990) The third international workshop on the standardisation of insulin autoantibody measurement. Diabetologia 33: 60-61

20. Kuglin B, Kolb H, Greenbaum C, Maclaren NK, Lernmark Å, Palmer JP (1990) The fourth international workshop on the standardisation of insulin autoantibody measurement. Diabetologia 33: 638-639

21. Lévy-Marchal C, Bridel MP, Sodoyez-Goffaux F et al. (1991) Superiority of radiobinding assay over enzyme-linked immunosorbent assay for detection of insulin autoantibodies in newly diagnosed type 1 diabetic patients. Diabetes Care 14:61-63

22. Greenbaum C, Palmer JP, Kuglin B, Kolb H and participating laboratories (1992) Insulin autoantibodies measured by RIA methodology are more related to IDDM than those measured by ELISA. J Clin Endocrinol Metab 74: 1040-1044

23. Dziarski R (1988) Autoimmunity: polyclonal activation or antigen induction? Immunol Today 9: $340-342$

24. Tomer Y, Shoenfeld Y (1988) Ageing and autoantibodies. Autoimmunity 1: 141-149

25. Laureys M, Sion JP, Slabbynck H et al. (1991) Macrocreatine kinase type 1: a serum marker associated with disease. Clin Chem 37: $430-434$

26. Decraene T, Vandewalle C, Pipeleers DG, Gorus FK and the Belgian Diabetes Registry (1992) Elevated IgM concentrations at onset of type 1 (insulin-dependent) diabetes: correlation with IgM binding to cells. Clin Chem 38: 1762-1769

27. National Diabetes Data Group (1979) Classification and diagnosis of diabetes mellitus and other categories of glucose intolerance. Diabetes 28: 1039-1057

28. Tan WP (1990) Insulin autoantibodies in newly diagnosed insulin-dependent diabetic patients. M. Sc. thesis, Vrije Universiteit Brussel, Brussels

29. Srikanta S, Ricker AT, McCulloch DK, Soeldner JS, Eisenbarth GS, Palmer JP (1986) Autoimmunity to insulin, beta cell dysfunction and development of insulin-dependent diabetes mellitus. Diabetes 35:139-142

30. Van Schravendijk CFH, Foriers A, Hooghe-Peters EL et al. (1985) Pancreatic hormone receptors on islet cells. Endocrinology 117: 841-848

31. Nakazato M, Asai J, Kangawa K, Matsukura S, Matsuo H (1989) Establishment of a radioimmunoassay for human islet amyloid polypeptide and its tissue content and plasma concentration. Biochem Biophys Res Commun 164: 394-399

32. Sodoyez JC, Koch M, Sodoyez-Goffaux F (1991) Anticorps antiinsuline: methodologie et implications cliniques. Diabète Métab $17: 255-269$

33. Bottazzo GF, Florin-Christensen A, Doniach D (1974) Islet cell antibodies in diabetes mellitus with autoimmune polyendocrine deficiencies. Lancet II: 1279-1283

34. Bonifacio E, Boitard C, Gleichmann H et al. (1990) Assessment of precision, concordance, specificity, and sensitivity of islet cell antibody measurement in 41 assays. Diabetologia 33: 731736

35. Karjalainen J, Knip M, Hyöty H et al. (1988) Relationship between serum insulin autoantibodies, islet cell antibodies and Coxsackie-B4 and mumps virus-specific antibodies at the clinical manifestation of type 1 (insulin-dependent) diabetes. Diabetologia 31: 146-152

36. Vardi P, Ziegler AG, Mathews JH et al. (1989) Concentration of insulin autoantibodies at onset of type 1 diabetes. Diabetes Care 11: $1320-1325$ 
37. Castaño L, Russo E, Zhou L, Lipes MA, Eisenbarth GS (1991) Identification and cloning of a granule autoantigen (carboxypeptidase-H) associated with type 1 diabetes. J Clin Endocrinol Metab 73: 1197-1201

38. Clark A, Yon SM, de Koning EJP, Holman RK (1991) Autoantibodies to islet amyloid polypeptide in diabetes. Diabetic Med 8: $668-673$

39. Sodoyez JC, Koch M, Lemaire I et al. (1991) Influence of affinity of antibodies upon their detection by liquid phase radiobinding assay and solid phase enzyme linked immunosorbent assay. Demonstration using monoclonal antibodies raised against rDNA humàn proinsulin. Diabetologia $34: 463-468$

40. Holmberg D, Coutinho A (1985) Natural antibodies and autoimmunity. Immunol Today 6:356-357

41. Theofilopoulos AN (1987) Autoimmunity. In: Stiter DP, Stobo JD, Wells JU (eds) Basic and clinical immunology. 6th edn. Appleton \& Lange, Norwalk, pp 128-158

42. Tarner JA, Getzoff ED, Paterson Y, Olson AJ, Lerner RA (1985) The atomic mobility component of protein antigenicity. Ann Rev Immunol 3: 501-535
43. Barlow PJ, Edwards MS, Thornton JM (1986) Continuous and discontinuous protein antigenic determinants. Nature 322: 747748

44. Westhof E, Altschuk D, Moras D et al. (1984) Correlation between segmental mobility and the location of antigenic determinants in protein. Nature 311:123-126

45. Fineberg SE, Rathbun MJ, Hufferd S et al. (1988) Immunologic aspects of human proinsulin therapy. Diabetes $37: 276-280$

Received: 15 April 1992

and in revised form: 15 July 1992

Dr. F. K. Gorus

Department of Metabolism and Endocrinology

Vrije Universiteit Brussel

Laarbeeklaan 103

B-1090 Brussels

Belgium 